\title{
Eficiência do uso da água em métodos de combate a incêndios em florestas plantadas
}

\author{
Weslen Pintor CANZIAN ${ }^{1 *}$, Nilton Cesar FIEDLER ${ }^{1}$, Edmilson Bitti LOUREIRO², Leandro Christo BERUDE ${ }^{1}$ \\ ${ }^{1}$ Universidade Federal do Espírito Santo, Jerônimo Monteiro, ES, Brasil \\ ${ }^{2}$ Coordenação de Proteção Florestal, Fibria Celulose S. A., Aracruz, ES, Brasil. \\ *E-mail: fiedler@pq.cnpq.br
}

Recebido em abril/2017; Aceito em novembro/2017.

\begin{abstract}
RESUMO: O incêndio florestal é um dos maiores danos que as florestas estão sujeitas, e em geral, a maior dificuldade no seu combate está relacionada com a disponibilidade de água nas proximidades da ocorrência. Neste contexto, o objetivo desta pesquisa foi analisar a eficiência do uso da água em três diferentes métodos de combate a incêndios florestais (Kit combate, CAF'S e caminhão pipa convencional) em áreas de eucalipto no norte do Espírito Santo e sul da Bahia. Em cada um dos métodos foram analisados os seguintes parâmetros: vazão, tempo de uso total, tempo de uso para cada 1.000 litros de água, rendimento e volume total disponível. Todos os parâmetros avaliados apresentaram diferença estatística pelo teste de Tukey a 5\% de probabilidade. O sistema CAF'S com a tecnologia de espuma pressurizada obteve os melhores índices, uma vez que, apresentou bons resultados em todos os aspectos avaliados, sendo o principal deles a elevada capacidade de transformação do volume de água em espuma, proporcionando um grande volume total disponível.
\end{abstract}

Palavras-chave: proteção florestal, retardante de fogo, controle de incêndios.

\section{Efficiency of use of water in fire fighting in planted forests}

\begin{abstract}
The forest fire is one of the biggest damage that the forests are subject and the biggest difficulty in their fight is related to water availability near the occurrence. In this context, the objective of this research was to analyze the efficiency of water use when using combat kit, CAF'S and water truck in fighting forest fires. The study consisted of the analysis of three distinct fighting Forest fires systems (Kit combat, CAF'S and water truck), which were analyzed using the following parameters: flow, total usage time, usage time per 1,000 liters of water, incomeand total volume available. All parameters showed statistical differences by the Tukey test at $5 \%$ probability between combat systems and Technologies used. The CAF'S system with a pressurized foam technology achieved the best rates, since, showed good results in all aspects evaluated, the main one being the ability to transform the foam in water volume, providing a large total volume available.
\end{abstract}

Keywords: forest protection, fire retardant, fire control.

\section{INTRODUÇÃO}

Os incêndios florestais causam inúmeros danos aos ecossistemas florestais e têm importância ecológica fundamental pela sua influência sob a poluição atmosférica e mudanças climáticas (MARABOTI et al., 2016). Além do fator ambiental, Soriano et al. (2015) destacam que os impactos causados proporcionam problemas econômicos e sociais.

De acordo com Souza et al. (2012), incêndio florestal é um dos mais custosos e prejudiciais desastres ambientais do Brasil. Soares; Santos (2002) destacam que os incêndios florestais aparentam ser o maior desastre que o setor florestal pode passar.

Pereira et al. (2004) e Escrig et al. (2016) enfatizam a importância que os grandes incêndios florestais têm atingido nos últimos anos, que além de prejuízos econômicos e mudanças climáticas, podem levar a perda de vidas humanas.

Os órgãos florestais buscam inovação e evolução de tecnologias em todos os âmbitos a fim de proporcionar melhorias. Muitas vezes a substituição ou apenas o aprimoramento dos métodos tradicionais pode trazer benefícios imensuráveis. A implementação de novas técnicas, equipamentos e sistemas de combate a incêndios florestais visam proporcionar vantagens no triângulo da sustentabilidade, ou seja, nos aspectos sociais, ambientais e econômicos. Uma das maiores dificuldades encontradas no combate aos incêndios florestais é a baixa disponibilidade de água nas proximidades das ocorrências. Assim, o desenvolvimento de novos equipamentos capazes de aumentar o rendimento do volume de água a ser aplicado no combate aos incêndios florestais é extremamente importante.

De acordo com Fiedler et al. (2015) e Canzian et al. (2016), a água está cada vez mais escassa e torna-se essencial o uso de novos recursos que proporcionam maior rendimento no combate aos incêndios florestais torna-se essencial.

$\mathrm{O}$ conhecimento da eficiência dos diferentes sistemas de combate pode influenciar na tomada de decisões e no sucesso na extinção do fogo. $\mathrm{O}$ uso do recurso correto proporciona melhores resultados e menores gastos. Dessa forma, o objetivo desta pesquisa foi analisar a eficiência do uso da água em diferentes métodos utilizados no combate aos incêndios em florestas plantadas com eucalipto.

\section{MATERIAL E MÉTODOS}

A pesquisa foi realizada em áreas de plantios de eucalipto situadas no norte do estado do Espírito Santo e sul da Bahia. A coleta de dados foi realizada com três sistemas de combate direto de incêndios florestais, sendo no total, onze Kits 
combate, um CAF'S (“Compressed Air Foam System”) e três Caminhões pipa (Figura 1).
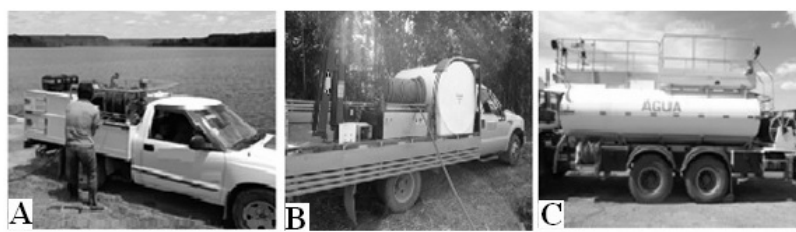

Figura1. Kit combate (A), CAF’S (B) e Caminhão pipa (C).

Figure 1. Combat kit (A), CAF'S (B) and water truck (C).

Os três sistemas de combate são caracterizados por apresentarem um veículo automotor para deslocamento e pressurização, um tanque reservatório para transportar a água que será utilizada no combate aos incêndios, além se um sistema de moto-bomba acoplado ao motor do veículo, com mangueira de aproximadamente 100 metros de comprimento equipada com bico regulável do tipo jato/leque para impulsionar a água no momento do combate. A mangueira dos sistemas de combate são de $3 / 4$ " de diâmetro para o Kit combate e caminhão pipa e de 1" de diâmetro para o CAF'S. Já a capacidade média de volume de água a ser transportada é de 600 litros para o Kit combate, 2.600 litros para o CAF'S e de 12.000 litros para os caminhões pipa.

Os caminhões pipa apresentam além desses itens, um canhão de jato d'água na parte superior do tanque reservatório que possibilita potencialmente a aplicação de água com vazão superior à aplicada pelas mangueiras entre todos os sistemas de combate.

Os Kits combate e os CAF'S não são equipados com canhão, entretanto, apresentam tecnologia de espuma pressurizada, possibilitando utilizar um sistema de bombeamento de água pura ou misturada com retardante de fogo em alta pressão. Nesses casos, o sistema de bombeamento é controlado por um aparelho que mede os níveis de água e de retardantes (Figura 2). Quando é acionado o uso do retardante, o dispositivo é programado para expelir uma mistura de água com retardante em alta pressão, transformando-a em uma espuma com alto poder de inibição das chamas (Figura 2).

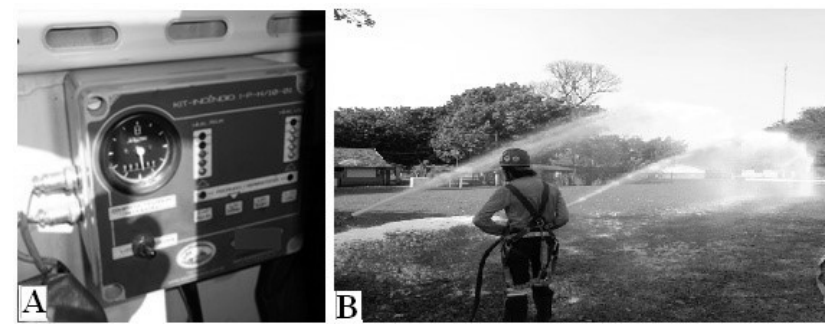

Figura 2. Medidor de nível de água e de retardante (A) e espuma pressurizada (B).

Figure 2. Water level meter and retardant (A) and pressurized foam (B).

Para medição dos volumes de água, foram realizadas três repetições de cada um dos sistemas de combate. Antes de cada teste, foi destinado a cada equipamento um tempo de dois minutos para a estabilização do volume lançado pelo sistema de moto-bombas. Com auxílio de um recipiente fechado com um único orifício, foi demarcado um tempo de 30 segundos para coleta do volume de água lançado pelo sistema. Cada repetição foi transferida para uma proveta graduada onde se pôde quantificar o volume de água de cada repetição (Figura 3).

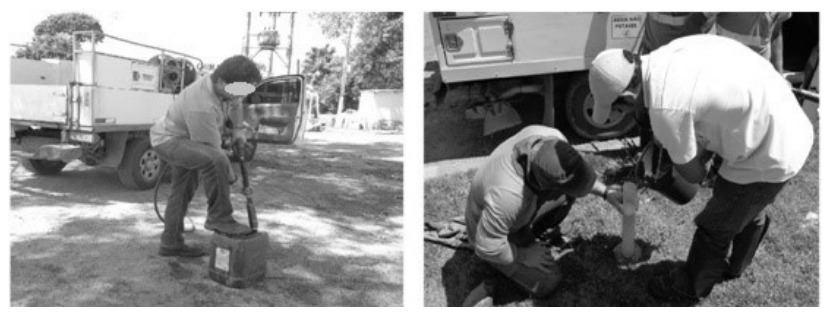

Figura 3. Procedimentos de medição das vazões.

Figure 3 . The flow measurement procedures.

Para a determinação do volume de espuma, foi destinado para cada equipamento um tempo de 2 minutos para a estabilização do sistema de moto-bombas. Foram realizadas três repetições em todos os Kits combate e CAF'S avaliados. Com auxílio de um reservatório de 200 litros e cronômetro, foi demarcado o tempo que cada repetição demorou para enchê-lo. Para quantificar a transformação do volume de água pelo volume de espuma aplicado, cada amostra foi lacrada para decantação da água que estava em suspensão em meio à espuma. Após estabilização da água, foi medido o volume, para dessa forma, saber o quanto se consumiu de água para geração de um determinado volume de espuma.

A medição da vazão dos canhões foi realizada pela diferença do volume de água do tanque pelo tempo de lançamento de água. A diferença do volume do tanque foi medido com o uso de uma régua graduada, que mede a quantidade real de água no tanque. $\mathrm{O}$ teste foi realizado em três caminhões pipa.

Com os dados experimentais obtidos, foi avaliada a normalidade dos erros pelo teste de Shapiro-Wilk. Em seguida, os dados foram submetidos à análise de variância. Quando o valor de "F" foi significativo, as médias dos tratamentos foram submetidas ao teste de Tukey ao nível de $5 \%$ de significância para descobrir se existe diferença entre os métodos de combate.

\section{RESULTADOS}

De acordo com Aseretto et al. (2013), não basta ter apenas informações sobre os incêndios florestais, mas sim informações harmonizadas. Assim, para obtenção de bons resultados no combate aos incêndios florestais é necessário que os recursos disponíveis sejam suficientemente capazes de corresponder quando solicitados e que estejam sempre em boas condições de uso, ou seja, são necessárias manutenções e avaliações periódicas desses sistemas.

Os recursos avaliados apresentaram grandes disparidades entre si nos aspectos analisados. Na Tabela 1 estão as médias obtidas nas avaliações.

\section{DISCUSSÃO}

Os diferentes sistemas de combate apresentaram diferentes capacidades de transporte de volume de água. Os caminhões-pipas apresentaram maiores capacidades de transporte, seguidos pelos CAF'S e os Kits. O volume a ser transportado depende diretamente da capacidade de carga de cada veículo transportador. Assim, os resultados foram dentro do esperado, visto que, os caminhões apresentaram maiores capacidades de carga que os CAF'S e os Kits combate. 
Tabela 1. Médias dos parâmetros analisados em cada sistema de combate.

Table 1. Averages of the parameters analyzed in each combat system.

\begin{tabular}{ccccccc}
\hline Sistemas & Volume (L) & $\begin{array}{c}\text { Vazão } \\
\left(\mathrm{L} . \mathrm{min}^{-1}\right)\end{array}$ & $\begin{array}{c}\text { Tempo de uso } \\
(\text { min. })\end{array}$ & $\begin{array}{c}\text { Tempo de uso a cada } \\
1.000 \text { litros (min.) }\end{array}$ & $\begin{array}{c}\text { Rendimento por } \\
\text { litros de água (L) }\end{array}$ & $\begin{array}{c}\text { Volume total } \\
\text { disponível (L) }\end{array}$ \\
\hline Kit - mangueira (A) & 600 & $19,67 \mathrm{~A}$ & $30,50 \mathrm{~A}$ & $50,64 \mathrm{C}$ & 1,00 & $600,00 \mathrm{~A}$ \\
\hline Kit - mangueira (E) & 600 & $91,84 \mathrm{~B}$ & $37,50 \mathrm{~A}$ & $62,25 \mathrm{D}$ & 5,77 & $3.459,81 \mathrm{~B}$ \\
\hline CAF'S - mangueira (A) & 2.600 & $25,10 \mathrm{~A}$ & $103,59 \mathrm{~A}$ & $39,84 \mathrm{BC}$ & 1,00 & $2.600,00 \mathrm{AB}$ \\
\hline CAF'S - mangueira (E) & 2.600 & $263,30 \mathrm{C}$ & $118,34 \mathrm{~A}$ & $45,52 \mathrm{BC}$ & 12,01 & $31.216,64 \mathrm{D}$ \\
\hline Pipa - mangueira (A) & 9.125 & $31,90 \mathrm{~A}$ & $344,43 \mathrm{~B}$ & $37,75 \mathrm{~B}$ & 1,00 & $9.125,00 \mathrm{C}$ \\
\hline Pipa - canhão (A) & 8.000 & $409,10 \mathrm{D}$ & $19,55 \mathrm{~A}$ & $2,44 \mathrm{~A}$ & 1,00 & $8.000,00 \mathrm{C}$ \\
\hline
\end{tabular}

(A) - água; (E) - espuma; Médias seguidas por uma mesma letra, em cada coluna, não diferem estatisticamente (Tukey, $\mathrm{p}>0,05)$.

Especificamente em incêndios florestais, sistemas de combate com volume de água muito grandes podem ser prejudiciais, pois, na maioria das vezes, as ocorrências de incêndios são em locais de difícil acesso, o que dificulta o transporte de veículos pesados. Logo os CAF'S e os Kit combate se destacam por apresentar maior mobilidade e rapidez de deslocamento. De acordo com Martins et al. (2010), as melhores opções de veículos de combate a incêndios florestais apresentam possibilidade de carga de 2.500 a 3.000 litros de água.

A vazão de um sistema de combate aos incêndios florestais determina a quantidade de líquido lançado por determinado tempo. É de extrema importância o conhecimento desses valores para avaliação e planejamento do recurso a ser utilizado em um determinado incêndio. Dessa forma, pode-se evitar que os recursos de combate se esgotem antes de combater totalmente o incêndio.

Pode-se perceber a superioridade dos canhões dos caminhões-pipa sobre os demais recursos, seguidos respectivamente pelos CAF'S e os Kit combate com a aplicação de espuma pela mangueira. Além disso, foi possível verificar que os diferentes sistemas com aplicação de apenas água pela mangueira apresentam os piores resultados. A vazão do canhão dos caminhões pipa equivale em média a $12,83,16,29$ e 20,79 vezes a vazão do combate com mangueira com água dos Pipas, CAF'S e dos Kits respectivamente. Em situações em que necessitam de altos volumes de água, o recurso mais recomendado é a utilização dos caminhões pipa com o acionamento do canhão por apresentar a maior vazão. Dessa forma, o caminhão pipa com o emprego do canhão apresenta melhores características para incêndios que necessitam de altos volumes de água em curto intervalo de tempo e em áreas próximas das estradas ou de fácil acesso.

O volume a ser aplicado pelos sistemas de combate deve ser considerado no controle de um incêndio florestal. Entretanto, o tempo que o recurso suporta em frente a um combate é outro fator muito importante.

O caminhão pipa utilizando somente a mangueira é o sistema de combate que consegue aplicar um volume de água constante por mais tempo, chegando a 344 minutos de combate. $\mathrm{O}$ fato de apresentar em média a maior capacidade de volume de transporte e armazenamento de água em seu tanque, associado à baixa vazão, o diferenciou estatisticamente ao nível de $5 \%$ de probabilidade pelo teste Tukey dos demais recursos utilizados.

Apesar dos demais sistemas de combate não diferenciarem significamente, recursos que têm capacidade de combater um incêndio por mais tempo devem ser considerados. Nesse caso, o CAF'S utilizando a mangueira em ambas as situações, espuma e água, são mais recomendados que os outros sistemas de combate.

Embora o caminhão pipa utilizando o canhão tenha apresentado em média a segunda maior capacidade de volume no tanque, seu tempo de uso é reduzido pela alta vazão, isso o faz um recurso de aplicação de altos volumes em pequeno tempo de combate.

Para avaliar os sistemas de combate de maneira padronizada, os valores de tempo de uso foram padronizados para tempo de uso a cada 1.000 litros de água disponível.

Avaliando os sistemas de combate neste aspecto, pode-se perceber o real potencial de uso. Dessa forma o Kit com a aplicação de espuma com a mangueira apresentou diferença estatística ao nível de $5 \%$ de probabilidade pelo teste Tukey dos demais sistemas de combate. Nessas condições o uso da mangueira pelo caminhão pipa deixa de ser a melhor opção para ser a segunda menos eficiente. Outro aspecto a se considerar é o fato de que a utilização da espuma proporciona um aumento do tempo de uso da água (a cada 1.000 litros) de $22,72 \%$ no Kit e de $14,12 \%$ no CAF'S sobre o uso apenas de água.

Alguns sistemas de combate apresentam capacidade de transformação do volume de água transportado em volume de espuma para aplicação no combate a incêndios. Essa transformação de volume aumenta a eficiência de um combate, uma vez que o volume de água transportado é aumentado. Pode-se perceber que, o volume total disponível foi alterado somente nos equipamentos que têm a possibilidade de aplicar retardante de fogo misturado com a água em alta pressão. Dessa forma, apenas dois sistemas aumentaram o volume total disponível, sendo o Kit e o CAF'S com aplicação de espuma pela mangueira.

Neste caso pode-se observar que o CAF'S utilizando a tecnologia de transformação de água em espuma para o combate dos incêndios florestais é o melhor sistema entre os avaliados, pois têm maior volume disponível transportado para ser utilizado. $\mathrm{O}$ poder de transformação do volume total transportado de água para o volume total disponível na hora do combate pelo Kit e o CAF'S é de 5,77 e 12,01 quando se utiliza a tecnologia de aplicação de espuma.

O CAF'S com a utilização de espuma apresentou superioridade sobre os demais recursos avaliados, uma vez que, gerou a segunda melhor vazão e tempo médio de uso, além da maior capacidade de transformação de água em espuma, o que aumentou o volume total disponível. Esse último fator é uma das maiores dificuldades no combate aos incêndios florestais, devido à baixa disponibilidade de água nas proximidades das ocorrências. 


\section{CONCLUSÕES}

Entre os sistemas de combate testados o que apresentou maior eficiência no uso da água foi o CAF'S com a aplicação de espuma, com destaque para sua capacidade de transformação do volume de água em espuma, proporcionando um grande volume total disponível no momento do combate ao incêndio florestal.

\section{REFERÊNCIAS}

ASERETTO, D. R.; RIGO, D. de.; LEO, M. D.; CORTÉS, A.; AYANZ, J. S. M. A data-driven model for large wildfire behaviour prediction in Europe. Procedia Computer Science, v. 18, p. 1861-1870, 2013. DOI: https://doi.org/10.1016/j.procs.2013.05.355

CANZIAN, W. P.; FIEDLER, N. C.; BRINATE, I. B.; JUVANHOL, R. S.; BIGHI, K. N. Diferentes concentrações de retardante de fogo em plantios de eucalipto. Nativa, Sinop, v.4, n.4, p.195-198, 2016. DOI: http://dx.doi.org/10.14583/2318-7670.v04n04a02

ESCRIG, A.; LIZ, J. L.; CATALÀ, J. Innovative to create active and passive protection layers against forest fires. XIV Florestal Mundial CONGRESS, Durban, África do Sul, p. 7-11 2015.

FIEDLER, N. C.; CANZIAN, W. P.; MAFIA, R. G.; RIBEIRO, G. A.; JUNIOR, J. K.Intensidade de queima de diferentes retardantes de fogo. Revista Árvore, Viçosa, v.39, n.4, p.691-696, 2015. DOI: http://dx.doi.org/10.1590/0100-67622015000400011
MARABOTI, V. M.; GONÇALVES, S. B.; CANZIAN, W. P.; FIEDLER, N. C.; MENDONÇA, A. R. Fire retardantes different efficiency in eucalyptus plantations in the south of Espírito Santo, Brazil. Australian Journal of Basic and Applied Sciences. v.10, n.9, p. 24-29, 2016.

MARTINS, R. N.; OLIVEIRA, G. A. G. de.; ARAÚJO, J. A. P. L. de. Apoio no gerenciamento da execução do plano de ação do programa de desenvolvimento florestal do Vale do Parnaíba (PDFLOR-PI). Apostila do curso técnicas de prevenção e combate à incêndios florestais. 51 f. Curitiba, PR, 2010.

PEREIRA, C. A.; FIEDLER, N. C.; MEDEIROS, M., B. de. Análise de ações de prevenção e combate aos incêndios florestais em unidades de conservação do cerrado. Floresta. v. 34, n. 2, p. 95-100, 2004.DOI: http://dx.doi.org/10.5380/rf.v34i2.2378

SOARES, R. V.; SANTOS, J. F. Perfil dos incêndios florestais no Brasil de 1994 a 1997. Floresta, Curitiba, v. 32, n. 2, p. 219-232, 2002. DOI: http://dx.doi.org/10.5380/rf.v32i2.2287

SORIANO, B. M. A.; DANIEL, O.; SANTOS, S. A. Eficiência de índices de risco de incêndios para o pantanal sul-mato-grossense. Ciência Florestal, Santa Maria, v.25, n.4, p.809-816, 2015. DOI: http://dx.doi.org/10.5902/1980509820231

SOUZA, H. N. de.; ARAÚJO, T. G. de.; RIBEIRO, GUIDO, A. R. Avaliação da eficiência de um gel hidroretentor como retardante de fogo. Revista Árvore, Viçosa, v.36, n.3, p.471-477, 2012. DOI: http://dx.doi.org/10.1590/S0100-67622012000300009 